\title{
Creating a Coral Symphony: Sound Art and Sonification
}

\author{
Robert Johnstone
}

James Cook University

\begin{abstract}
.
There is a rich history of artists representing the visible world through imagery. What of the invisible? What if you could harness hidden voices of the natural environment? Artistic sonification is an emerging artistic endeavour at the intersection of mathematics and music, which sees big data transformed into sound. This paper describes the background and development of Coral Symphony - a Sound Art installation unveiling voices from the Great Barrier Reef, Australia. Installation constituent materials evolved from the sonification of ecological data over twenty years, supplemented with field recordings.
\end{abstract}

\section{Introduction}

$\mathrm{M}$ uch debate surrounds the nature and definition of "Sound Art". The term itself emerged much later than the first examples of artwork in the field (Licht "Origins" 3; Engström and Stjerna 14; Cox 19). Most authors agree that Sound Art has a unique approach to space and time (Licht "Origins" 3); a demonstrated understanding of sound in itself (Cox 19); and an encouragement of aural awareness (Kolber 43). Others argue that "much of what has been called 'Sound Art' has not much to do with either sound or art." (Neuhaus 1). Recent research suggests that Sound Art works between categories; it moves back and forth between art and electronic music worlds; embracing the digitisation of sound, art, space and relations (Licht "Origins" 9).

The art form's history has been both personal and piecemeal; without a clear linear trajectory in time, location or personage (Licht "Origins" 3). The disparity in chronology of prominent artists is particularly marked, many synthesising their oeuvre before the wholesale adoption of the term by art galleries and museums. Indeed the term Sound Art was not conceived until 1982, some decades after the first works. At the time, Max Neuhaus (Neuhaus 1) cautioned against the temptation to freely label the emerging and experimental use of music and sound as Sound Art. As a term and a category, he maintained, it did not constructively supplement existing categories such as music or sculpture (Neuhaus 1).

The task of illuminating the art is further complicated upon scrutiny of the media harnessed by influential artists in the field, many of whom use sound in conjunction with other innovative elements and sensory modes (Kahn 2). That the artists involved in Sound Art are from many different backgrounds (music, theatre, film, technology, engineering) further accentuates the complexity in attempting to corral the term. Rudi (1) suggests that the art is an evolutionary beast, emerging from works more easily categorised in terms of installation art, soundscape, poetry, film and new media; further confirming the fragmentary rise of Sound Art from a heaving artistic soup.

The fragmentary and ever-evolving nature of Sound Art and its taxonomic freedom are perhaps its greatest seductions; seducing arts beyond its ken, degrading resolution and clarity of 
form. Licht ("Between Categories" 12) identifies the temptation to apply the term to any experimental music of the latter part of the twentieth century, particularly to Cage and his successors. For the popular media the term is reasonably synonymous with any experimental music (Engström and Stjerna 14). For Kahn, Sound Art is a subsidiary topic within sound, aurality and modern art; a part of the synthetic nature of the arts, "the various intersecting social, cultural, and environmental realities wittingly and unwittingly embodied in any one of the innumerable factors that go into producing, experiencing, and understanding a particular work" (1).

Whilst the nature, and thus definition of Sound Art remains elusive, the art form has been consolidating its presence within cultural and academic arenas since the 1960s. Sound Art as an ex post facto categorisation has flourished, and continues to do so in this broadness and complexity. The intersection and collision of a multiplicity of disciplines allows for an inception, expression and manifestation that other art forms cannot reach. Perhaps Sound Art can be best understood as a "sonification of artistic ideas, or sonic representations of the same" (Rudi 1). We move beyond the limits of traditional art categories; a sea-change empowering the free-flowing genesis of new media; a change that we are yet to fully fathom.

\section{Sonification}

Data sonification, or the mapping of data to sound, first emerged in the literature on computer-human interfaces. The field has developed rapidly in recent decades, with a growing community of researchers focused on the meaningful, data driven creation of sound (Hansen and Rubin 1). A subset of this community engages in artistic sonification. Working across multiple disciplines (music, mathematics and computer science) they work with data as the constituent material of Sound Art.

In a recent attempt at a definition of sonification, Hermann (1) suggested "Sonification is the data-dependent generation of sound, if the transformation is systematic, objective and reproducible". Such generation of sound has a long utilitarian history. One can consider sonar and the Geiger counter. The data-driven sounds these devices produce convey meaning, but is there meaning beyond the utilitarian?

In the 21st century, experimental sound and new media artists are invigorating the traditional arts. In its seduction of new media, Sound Art is flirting with sonified data, almost as found sound. As recently as August 2011, Gresham-Lancaster highlighted the limited research investigating the use of sonification as a means of artistic expression and found that it "is a powerful, poorly defined and under examined part of the field. It requires inclusion, support and research as much and possibly more than any other aspect of this field" (212).

Artistic sonification naturally engages in the discussion of sound and aesthetics. In what sense are any outputs from the transformation of large datasets more pleasing to the ear than a looped Geiger counter? The author's approach focuses on the natural beauty inherent in the data; the regular rhythms of tides; temperatures and seasons; the use of repetition such that events become self-referencing; and the algorithmic arrangement of harmonic relations between events. Importantly, as the raw materials of sonification increasingly stem from our virtual or digital surroundings, the challenge to the sonification process is to represent something that lacks a natural sonic reference point; and to create sounds that direct the viewer's gaze to the source rather than sounds experienced in other contexts. "A sonification that 
works is therefore the successful struggle to create a message that points beyond the medium" (Grond and Hermann 221).

Here is the challenge for sonification. To what extent can sounds that emerge from a stream of code be more than utilitarian? To what extent can sonification effect an aesthetic transmutation, allowing for engagement with sound and source together? Finally, to what extent can it be a potent artistic experience?

\section{Installation}

From its point of inception in 2012, Coral Symphony has revelled in the broadness and complexity of its intended form; an endeavour at the intersection of mathematics and music, which sees big data transformed into sound; sonification as art. The work uses data derived from water, in this case the waters of the Great Barrier Reef, and focuses on the beautiful simplicity of the reef waters in flux and how, through the translation of energy from one form of data to another, we can experience this motion in extraordinary ways.

Working within this digital stream, the approach is attuned to the 'Cagean' yearning that all sounds be listened to as music. Coral Symphony is being developed to be site specific and in dialogue with the surrounding space. The installation will incorporate advanced technology to create an abstract sound exposure - avant-garde and ephemeral; transient in essence; encouraging the audience to interact with the sonic motion of the reef. The sounds will be presented both as an installation and social event. The introduction of motion sensors within the installation space will allow the viewer to interact with the sonic motion of the reef. Sound will occur among bodies; as a social event (LaBelle 21).

Within the installation space two experiences will be presented:

1. The strange sounds of the reef. The soundtrack of the room will be the sonification of reef data collected at Myrmidon Reef on the Great Barrier Reef by the Australian Institute of Marine Science. The installation will give voice to the reef; to render reef data audible (see fig. 1). The work will seek to convey the sense of diurnal change on the reef, the scale of change and a sense of momentary dynamics. Data functions as a found object; revealing another realm; rich and strange.

2. The rich sounds of the reef. An interactive environment will be created where participants are free to move around the gallery space. When proximate to the interactive motion capture point, participants will be encouraged to augment the soundtrack of the room. The sounds they fashion will be added to the overall soundtrack emerging into the gallery space.

In this space, the movements of the body will function as an instrument. This will be achieved by using motion-tracking technology. Different movements will access different sound modules. Sound modules will include noises sampled from the reef and sounds recorded by an Autonomous Multichannel Acoustic Recorder that is currently moored at a depth of $20 \mathrm{~m}$ at the reef near Townsville. These sounds will be collected as part of a collaboration with the James Cook Centre for Sustainable Tropical Fisheries and Aquaculture. Modules will include the sounds of fish, crustaceans, whales, dolphins, and human noise on the reef. 


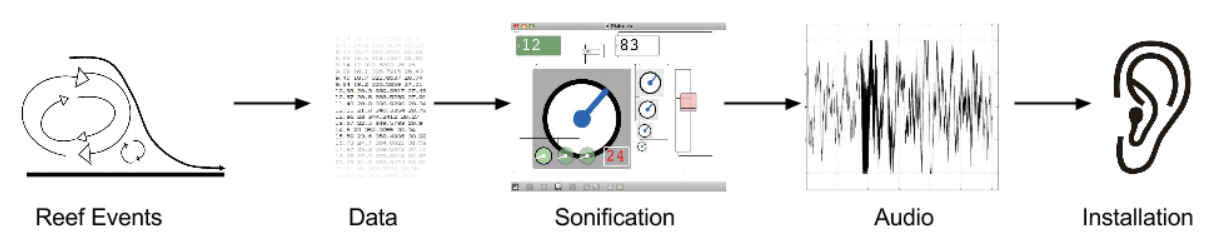

Figure 1 Current approach to reef data sonification.

A proof of concept sonification of reef data is available online (Johnstone 1). These sketches demonstrate the feasibility of the current approach to transforming data captured at the reef. Four sketches are presented. The first three use unique data sources (water temperature; air temperature; and wind speed at the reef). The fourth sketch demonstrates the current approach of 'layering' sonification tracks. Within the installation, multiple tracks will be played simultaneously within a consistent rhythm of diurnal, seasonal and annual movement in time. Additional recordings of sonification sketches that incorporate sampled sounds from the reef are continually emerging as part of the artistic process.

As a musical creation, Coral Symphony will be completely unique; built from the sonification of annual data cycles of Myrmidon Reef, synthesised with sampled sounds generated by installation participants to make long sonic tapestries. The audience listen; create; and perform. The installation will present data captured over twenty years. The breadth of coverage allows the author to explore sound, time and space; spanning the microscopic to the infinite; a palette ranging from changing tides to sine waves; the depths of the ocean to binary infinitum. Coral Symphony aims to be at the forefront of this extraordinary new media amalgam; part of the evolving nature of Sound Art.

\section{Future Work}

An important component of the installation will be to explore audience impressions and reactions. Within a framework of discovery-oriented qualitative interviews, audience participants will explore their impressive, significant or valued events. Within the scope of the current research, three key opportunities have emerged:

\section{Engagement and Participation}

Following the proof of concept of installation interactive technologies, Coral Symphony will be considered within the context of participation and interaction. The installation will be 
'open': it will leave gaps for the audience to engage with via active interpretation, or actual engagement and co-creation. Do these participatory processes support new roles and forms of engagement for sound art participants? As enablers of authorship, what is the role of interaction technologies in reinterpreting the visitor world, and enhancing artistic engagement?

\section{Sonic Ecology}

Sound Artist and conservationist David Dunn has suggested that "we require new modes of experience that can help recover those aspects of human integrity that are rooted in a fundamental sense of connectedness with the non-human world' (Dunn 4). The development of sonification works interpreting environmental data, including elements of the natural soundscape, may have the potential to open alternative pathways to environmental understanding (Polli 267). Can sound-based music nourish an eco-critical debate? Is there a role for sonic ecology in art? Can sound art encourage ecological understanding, especially in the context of the environmental debate? In revealing aspects of a hidden underwater world, can Sound Art be a call to change?

\section{Sound Art and Aesthetics}

Finally, within the context of Sound Art, the aesthetics, functionality and performance of the employed sonification techniques will be critiqued. To what extent can this critique engage with the existing philosophies of sound? When environmental data is re-situated and transformed to function as the constituent material of sound art, what aesthetic conventions should be considered?

\section{Conclusions}

Initial sonification trials using environmental data collected at the Great Barrier Reef, Australia have resulted in the presentation of successful sonification proofs. Coral Symphony will be open to the public in 2014 and incorporate design elements as presented in these trials. Transformed data will fill the installation with sounds rich and strange, providing an artistic lens through which to explore the potential of the form to open our ears to the natural world. As Sound Art, the work drives an emerging artistic discipline; with an emphasis on "sound" as a specific category; sound that reveals and transforms place; with a palette ranging from sine waves to silence; from digital detritus to the flows of the ocean; an experience of ardent listening. Coral Symphony is the essence of a form flourishing in tumult; a tumult electrified by the digitisation of sound, art, space and relations. The lightning swell of new media hauls the form to the forefront of artistic expansion and expression. It is an exhilarating juncture where sounds emerge to define, transform and bamboozle space. Riding the tide of digital detritus, this project aims to be harbinger of the ancient; revealing aspects of a hidden underwater world; enriching our aesthetic reception of sonified data; transforming space; encouraging people to pause and listen. 


\section{Works Cited}

Cox, Christoph. "Sound Art and the Sonic Unconscious” Organised Sound 14.1 (2009): 1926.

Dunn, David. "Sound Art and the Sacred" Terra Nova 2.3 (1997): 61-71.

Engström, Andreas, and Åsa Stjerna. "Sound Art or Klangkunst? A reading of the German and English literature on sound art" Organised Sound 14.1 (2009): 11-18.

Gresham-Lancaster, Scot. "Relationships of Sonification to Music and Sound Art" AI \& Society 27 (2011): 207-212.

Grond, Florian and Thomas Hermann. "Aesthetic Strategies in Sonification" AI \& Society 27 (2011): 213-222.

Hansen, Mark and Ben Rubin. "Babble Online: applying statistics and design to sonify the internet" Proceedings of the 2001 International Conference on Auditory Display (2001): 10-15.

Hermann, Thomas. Sonification - a Definition. http://sonification.de/son/definition Accessed 10 Oct 2013.

Johnstone, Robert. Coral Symphony: Sonification Sketches. youtube.com/user/coralsymphony, 2013.

Kahn, Douglas. "The Arts of Sound Art and Music” The Iowa Review, Feb. 2006. Accessed 10 Oct 2013.

Kolber, David. "Hildegard Westerkamp's Kits Beach Soundwalk: shifting perspectives in real world music" Organised Sound 7.1 (2002): 41-43.

LaBelle, Brandon. Background Noise: Perspectives On Sound Art. New York: Continuum International Publishing Group, 2006.

Licht, Alan. Sound Art: Between Music, Between Categories. New York: Rizzoli International Publications, 2007.

Licht, Alan. "Sound Art: Origins, development and ambiguities" Organised Sound 14.1 (2009): 3-10.

Neuhaus, Max. "Sound Art?" Introduction to the exhibition Volume: Bed of Sound PS 1 Contemporary Art Center, New York, July, 2000.

Polli, Andre. "Soundscape, Sonification, and Sound Activism" AI \& Society 27.2 (2012): 257-268.

Rudi, Joran. Editorial. Organised Sound 14.1 (2009): 1. 